University of Wollongong

Research Online

Australian Institute for Innovative Materials -

Papers

Australian Institute for Innovative Materials

2013

Critical behaviour of Ho2Fe17-xMnx-magnetisation and Mössbauer spectroscopy

Jianli Wang

University of Wollongong, jianli@uow.edu.au

\title{
S J. Campbell
}

University of New South Wales, stewart.campbell@adfa.edu.au

S J. Kennedy

ANSTO

S X. Dou

University of Wollongong, shi@uow.edu.au

Follow this and additional works at: https://ro.uow.edu.au/aiimpapers

Part of the Engineering Commons, and the Physical Sciences and Mathematics Commons

Research Online is the open access institutional repository for the University of Wollongong. For further information contact the UOW Library: research-pubs@uow.edu.au 


\title{
Critical behaviour of Ho2Fe17-xMnx-magnetisation and Mössbauer spectroscopy
}

\begin{abstract}
The magnetic properties of Ho2Fe17 - xMnx compounds $(x=0-2)$ of ferromagnetic ordering temperatures up to TC $\sim 344 \mathrm{~K}$ have been investigated by DC magnetization and Mössbauer effect measurements. The nature of the magnetic phase transitions and the critical behaviour around TC has been investigated by analysis of the magnetisation data and the critical exponents $\beta, \gamma$ and $\delta$ determined. The critical exponents are found to be similar to the theoretical values of the mean-field model for which $\beta=0.5$ and $\gamma=1.0$, indicating the existence of a long-range ferromagnetic interactions. The isothermal entropy changes $\Delta S$ around TC have been determined as a function of temperature in different magnetic fields.
\end{abstract}

\section{Keywords}

Magnetisation, Mössbauer spectroscopy, Critical exponents, Magnetocaloric, Ho2Fe17 - xMnx

Disciplines

Engineering | Physical Sciences and Mathematics

\section{Publication Details}

Wang, J. L., Campbell, S. J., Kennedy, S. J. \& Dou, S. X. (2013). Critical behaviour of Ho2Fe17-xMnxmagnetisation and Mössbauer spectroscopy. Hyperfine Interactions, 219 (1-3), 49-55. 


\title{
Critical Behaviour of $\mathrm{Ho}_{2} \mathrm{Fe}_{17-\mathrm{x}} \mathrm{Mn}_{\mathrm{x}}$ - Magnetisation and Mössbauer Spectroscopy
}

\author{
J.L. Wang ${ }^{1,2,3}$, S.J. Campbell ${ }^{3}$, S.J. Kennedy ${ }^{2}$ and S.X. Dou ${ }^{1}$ \\ ${ }^{1}$ Institute for Superconductivity and Electronic Materials, University of \\ Wollongong, Wollongong, NSW 2522 Australia \\ ${ }^{2}$ Bragg Institute, ANSTO, Menai, NSW 2234 Australia \\ ${ }^{3}$ School of Physical, Environmental and Mathematical Sciences, The University \\ of New South Wales, Canberra, ACT 2600 Australia
}

\begin{abstract}
The magnetic properties of $\mathrm{Ho}_{2} \mathrm{Fe}_{17-\mathrm{x}} \mathrm{Mn}_{\mathrm{x}}$ compounds $(\mathrm{x}=0-2)$ of ferromagnetic ordering temperatures up to $\mathrm{T}_{\mathrm{C}} \sim 344 \mathrm{~K}$ have been investigated by DC magnetization and Mössbauer effect measurements. The nature of the magnetic phase transitions and the critical behaviour around $\mathrm{T}_{\mathrm{C}}$ has been investigated by analysis of the magnetisation data and the critical exponents $\beta, \gamma$ and $\delta$ determined. The critical exponents are found to be similar to the theoretical values of the mean-field model for which $\beta=0.5$ and $\gamma=1.0$, indicating the existence of a long-range ferromagnetic interactions. The isothermal entropy changes $\Delta S$ around $T_{C}$ have been determined as a function of temperature in different magnetic fields.
\end{abstract}

Key words: Magnetisation, Mössbauer Spectroscopy, Critical Exponents, Magnetocaloric, $\mathrm{Ho}_{2} \mathrm{Fe}_{17-\mathrm{x}} \mathrm{Mn}_{\mathrm{x}}$

Corresponding Author:

Email: Stewart.Campbell@adfa.edu.au

Tel: +6126268 8767

Fax: +6126268 8786 


\section{Introduction}

Magnetic refrigeration based on the magnetocaloric effect (MCE) has attracted increasing attention in recent years due to advantages such as high efficiency and environmental safety compared with compressor-based refrigeration [e.g. 1, 2]. Considering scientific aspects and industrial applicability, the large gJ value in iron and the low cost of iron means that Fe-rich materials offer a potential choice as MCE materials for refrigerators [3, 4] and as a result, materials such as $\mathrm{R}_{2} \mathrm{Fe}_{17^{-}}$ based compounds have continued to attracted interest [5].

Recently we reported $[6,7]$ that the substitution of $\mathrm{Mn}$ for $\mathrm{Fe}$ in $\mathrm{Ho}_{2} \mathrm{Fe}_{17-\mathrm{x}} \mathrm{Mn}_{\mathrm{x}}$ compounds leads to a minimum of $\mathrm{M}_{\mathrm{S}}$ at $10 \mathrm{~K}$ and a maximum of $\mathrm{T}_{\mathrm{C}}$ in the composition dependence of $\mathrm{M}_{\mathrm{s}}($ at $\mathrm{T}=10 \mathrm{~K})$ and $\mathrm{T}_{\mathrm{C}}$ as well as the presence of strong magnetovolume effects below $\mathrm{T}_{\mathrm{C}}$. In order to better understand the nature of the magnetic phase transition around $\mathrm{T}_{\mathrm{C}}$ in these systems, we have carried out a detailed investigation of the critical behaviour by DC magnetization measurements and Mössbauer spectroscopy with the main findings reported here.

\section{Experimental}

The $\mathrm{Ho}_{2} \mathrm{Fe}_{17-\mathrm{x}} \mathrm{Mn}_{\mathrm{x}}$ compounds $(\mathrm{x}=0,0.5,1,2)$ were prepared by standard argon arc-melting (see [5-7] for details). The magnetic measurements were carried out in magnetic fields up to $6 \mathrm{~T}$ over the temperature range 5-350 $\mathrm{K}$ using a Physical Property Measurement System [6, 7]. ${ }^{57} \mathrm{Fe}$ Mössbauer spectra were obtained using a standard constant-acceleration spectrometer and a ${ }^{57} \mathrm{CoRh}$ source and the spectrometer calibrated at room temperature with an $\alpha$-iron foil.

\section{Results and Discussion}

3.1 Mössbauer Spectroscopy: Fig. 1 (a) shows the ${ }^{57}$ Fe Mössbauer spectra at 300 $\mathrm{K}$ for $\mathrm{Ho}_{2} \mathrm{Fe}_{17-\mathrm{x}} \mathrm{Mn}_{\mathrm{x}}(\mathrm{x}=0,0.5$ and 1.0). Given that the Curie temperatures for the $\mathrm{x}=0,0.5$ and 1.0 samples are above room temperature $-\mathrm{T}_{\mathrm{C}}=336 \mathrm{~K}, \mathrm{~T}_{\mathrm{C}}=344 \mathrm{~K}$ and $\mathrm{T}_{\mathrm{C}}=338 \mathrm{~K}$ respectively [7] - the $300 \mathrm{~K}$ spectra are found to exhibit spectral features characteristic of magnetic hyperfine splitting as expected. We have fitted the $\mathrm{Ho}_{2} \mathrm{Fe}_{17-\mathrm{x}} \mathrm{Mn}_{\mathrm{x}}$ spectra using the same approach applied to our analysis of 
$\mathrm{Dy}_{2} \mathrm{Fe}_{17-\mathrm{x}} \mathrm{Mn}_{\mathrm{x}}$ [5; see also 6]. As shown by Fig 1(a), satisfactory fits to the Mössbauer spectra were obtained using seven sub-spectra to represent the four inequivalent sites of the $\mathrm{Th}_{2} \mathrm{Ni}_{17}$-type structure (or the $\mathrm{Th}_{2} \mathrm{Zn}_{17}$ structure in brackets) - one sub-spectrum for the $4 \mathrm{f}(6 \mathrm{c})$ site, two for $6 \mathrm{~g}(9 \mathrm{~d})$, two for $12 \mathrm{j}$ (18f) and two for $12 \mathrm{k}(18 \mathrm{~h})$. The sub-spectra were assigned to the various sites by taking into account the nearest-neighbour environment of each respective site and the Fe-Fe distances [5].

The main hyperfine parameters at $300 \mathrm{~K}$ are listed in Table 1 . It can be seen that the isomer shifts follow the trends $\delta^{4 \mathrm{f}(6 \mathrm{c})}>\delta^{12 \mathrm{j}(18 \mathrm{f})}>\delta^{12 \mathrm{k}(18 \mathrm{~h})}>\delta^{6 \mathrm{~g}(9 \mathrm{~d})}$ for all compounds. The calculated Wigner-Seitz cell (WSC) volumes $\mathrm{V}_{\mathrm{ws}}$ for the $4 \mathrm{f}(6 \mathrm{c})$, $6 \mathrm{~g}(9 \mathrm{~d}), 12 \mathrm{j}(18 \mathrm{f})$ and $12 \mathrm{k}(18 \mathrm{~h})$ sites in $\mathrm{R}_{2} \mathrm{Fe}_{17}$ compounds have been shown to behave as follows: $\mathrm{V}_{\mathrm{ws}}{ }^{4 \mathrm{f}(6 \mathrm{c})}>\mathrm{V}_{\mathrm{ws}}{ }^{12 \mathrm{j}(18 \mathrm{f})}>\mathrm{V}_{\mathrm{ws}}{ }^{12 \mathrm{k}(18 \mathrm{~h})}>\mathrm{V}_{\mathrm{ws}}{ }^{6 \mathrm{~g}(9 \mathrm{~d})}[5,8]$. The present findings agree well with the previously observed relationship between isomer shift and WSC volumes, namely that the larger the WSC volume, the larger the isomer $\operatorname{shift} \delta[5,6]$.

Table 1 Mössbauer spectral hyperfine parameters for $\mathrm{Ho}_{2} \mathrm{Fe}_{17-\mathrm{x}} \mathrm{Mn}_{\mathrm{x}}$ at $300 \mathrm{~K}$. The errors for $\mathrm{B}_{\mathrm{hf}}$ and $\delta$ derived from the data fits are $\pm 0.1 \mathrm{~T}$ and $\pm 0.015 \mathrm{~mm} / \mathrm{s}$ respectively.

\begin{tabular}{|c|c|c|c|c|c|c|}
\hline Compounds & & $4 f$ & $6 g$ & $12 \mathrm{j}$ & $12 \mathrm{k}$ & Weighted Average \\
\hline \multirow[t]{2}{*}{$\mathrm{Ho}_{2} \mathrm{Fe}_{17}$} & $\mathrm{~B}_{\mathrm{hf}}, \mathrm{T}$ & 21.9 & 16.4 & 18.4 & 13.6 & 16.8 \\
\hline & $\delta, \mathrm{mm} / \mathrm{s}$ & 0.002 & -0.219 & -0.111 & -0.183 & -0.142 \\
\hline \multirow[t]{2}{*}{$\mathrm{Ho}_{2} \mathrm{Fe}_{16.5} \mathrm{Mn}_{0.5}$} & $\mathrm{~B}_{\mathrm{hf}}, \mathrm{T}$ & 22.8 & 17.1 & 17.3 & 12.6 & 16.2 \\
\hline & $\delta, \mathrm{mm} / \mathrm{s}$ & $s-0.054$ & -0.211 & -0.131 & -0.173 & -0.152 \\
\hline \multirow[t]{2}{*}{$\mathrm{Ho}_{2} \mathrm{Fe}_{16} \mathrm{Mn}$} & $\mathrm{B}_{\mathrm{hf}}, \mathrm{T}$ & 18.5 & 15.0 & 14.4 & 9.3 & 13.9 \\
\hline & $\delta, \mathrm{mm} / \mathrm{s}$ & -0.111 & -0.23 & -0.139 & -0.173 & -0.147 \\
\hline
\end{tabular}

The temperature dependences of the ${ }^{57} \mathrm{Fe}$ hyperfine interaction parameters for $\mathrm{Ho}_{2} \mathrm{Fe}_{16.5} \mathrm{Mn}_{0.5}$ are shown in Fig. 1(b) as a typical example of the behaviour of these compounds (see e.g., the similar behaviour of $\mathrm{Ho}_{2} \mathrm{Fe}_{17} \mathrm{Mn}$ [6]). The isomer shifts are found to behave as $\delta^{4 \mathrm{f}}>\delta^{12 \mathrm{j}}>\delta^{12 \mathrm{k}}>\delta^{6 \mathrm{~g}}$ at all temperatures with the 
decrease in isomer shift with increasing temperature following behaviour typical of the second-order Doppler shift. The dashed line through the average isomer shift values in Fig. 1(b) represents the calculated result based on a Debye model [e.g. 9] using Debye temperature $\theta_{D}=450 \mathrm{~K}$.
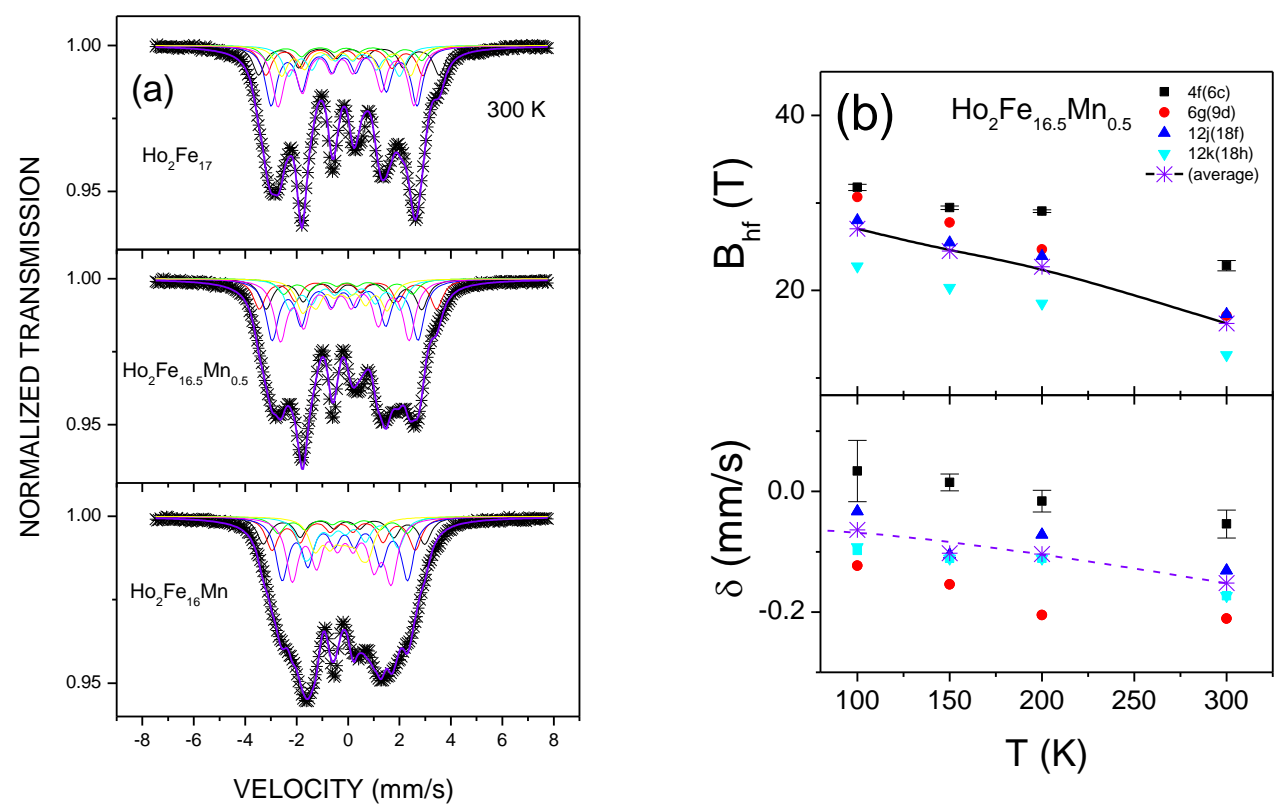

Figure 1 (a) $300 \mathrm{~K}$ Mössbauer spectra of $\mathrm{Ho}_{2} \mathrm{Fe}_{17-\mathrm{x}} \mathrm{Mn}_{\mathrm{x}}$ with $\mathrm{x}=0,0.5$ and 1.0. The fits and sub-spectra are described in the text.

(b) The temperature dependences of the magnetic hyperfine field and isomer shift values for the various sites of $\mathrm{Ho}_{2} \mathrm{Fe}_{16.5} \mathrm{Mn}_{0.5}$ with the average values of hyperfine field and isomer shift also shown. The full line acts as a guide to the eye for the average hyperfine field values. The dashed line represents the second-order Doppler shift calculated with Debye temperature $\theta_{D}=450 \mathrm{~K}$ as discussed in the text.

3.2 Critical Magnetic Transition: As below, we have carried out a detailed analysis of the magnetisation data around $T_{C}$ to investigate further the nature of magnetic phase transition in these compounds. The magnetisation data have been presented elsewhere $[6,7]$ with the analytical approach following that described in the critical magnetic study of $\mathrm{TbNi}_{2} \mathrm{Mn}[9]$.

According to the conventional static scaling law, the critical properties of a second-order magnetic transition can be described by the critical exponents $\beta, \gamma$ 
and $\delta$ derived from magnetization measurements around the transition temperature [e.g. 10]. The exponents can be expressed by the following equations:

$$
\begin{array}{ll}
M_{S}(T)=M_{0}\left|\left(T-T_{C}\right) / T_{C}\right|^{-\beta,}, & \text { for } \mathrm{T}<\mathrm{T}_{\mathrm{C}} \\
\chi_{0}^{-1}(T)=\left(h_{0} / M_{0}\right)\left(T-T_{C} / T_{C}\right)^{\gamma}, & \text { for } \mathrm{T}>\mathrm{T}_{\mathrm{C}} \\
M=D H^{1 / \sigma}, & \text { for } \mathrm{T}=\mathrm{T}_{\mathrm{C}}
\end{array}
$$

where $M_{0}, h_{0} / M_{0}$ and $D$ are the critical amplitudes [10] and $M_{s}$ and $\chi_{0}{ }^{-1}$ are derived by linear extrapolation from the high-field regions to the intercepts. Using the Kouvel-Fisher method - in which the quantities $\mathrm{M}_{\mathrm{s}}\left(\mathrm{dM}_{\mathrm{s}} / \mathrm{dT}\right)^{-1}$ and $\chi_{0}\left(\mathrm{~d} \chi_{0} / \mathrm{dT}\right)^{-1}$ are plotted against temperature with straight lines of slopes $1 / \beta$ and $-1 / \gamma$ expected [e.g. 11] - the values of $\beta=0.45, \gamma=0.95$ and $T_{C}=337 \mathrm{~K}$ have been derived for $\mathrm{Ho}_{2} \mathrm{Fe}_{16} \mathrm{Mn}$ as shown in Fig. 2(b). It is clear that the value of $\mathrm{T}_{\mathrm{C}}$ derived in this way for $\mathrm{Ho}_{2} \mathrm{Fe}_{16} \mathrm{Mn}$ is very close to the value $\mathrm{T}_{\mathrm{C}}=338 \mathrm{~K}$ determined from the $\mathrm{M}$ $\mathrm{T}$ curves $[6,7]$. Indeed this agreement between the $\mathrm{T}_{\mathrm{C}}$ values - determined directly from the magnetisation data and derived here from the critical exponent analysis confirms the applicability of the power laws to these $\mathrm{Ho}_{2} \mathrm{Fe}_{17-\mathrm{x}} \mathrm{Mn}_{\mathrm{x}}$ systems.
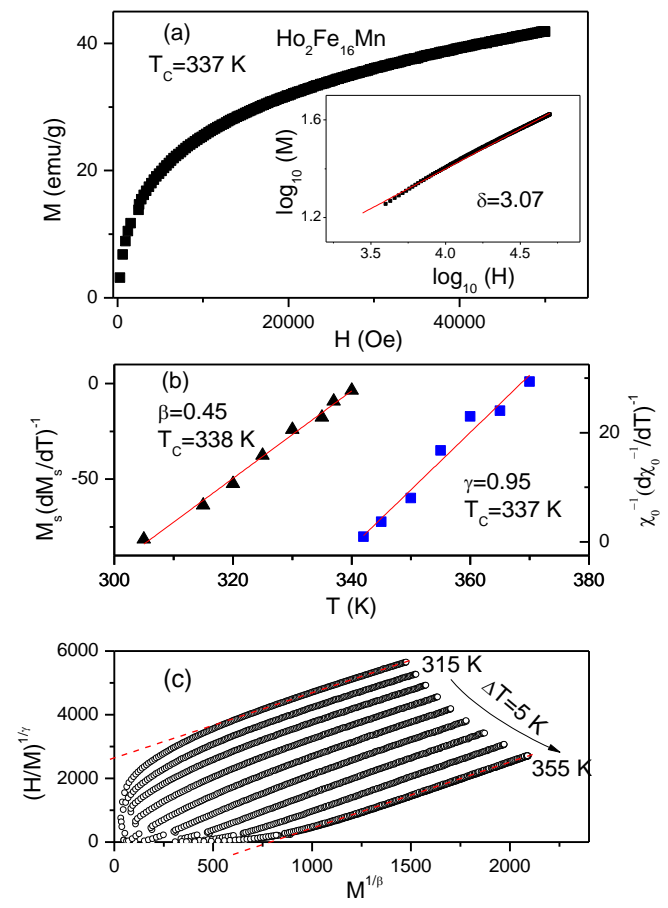
Fig. 2 (a) The critical isotherm analysis at $\mathrm{T}_{\mathrm{C}}=337 \mathrm{~K}$ for $\mathrm{Ho}_{2} \mathrm{Fe}_{16} \mathrm{Mn}$. The inset shows the data plotted on a double logarithmic scale with the fitted line through the data leading to the exponent $\delta=3.07$ as described in the text.

(b) Kouvel-Fisher plots of $\mathrm{M}_{\mathrm{s}}(\mathrm{T})\left(\mathrm{dM}_{\mathrm{s}} / \mathrm{dT}\right)^{-1}$ (left) and $\chi_{0}^{-1}(\mathrm{~T})\left(\mathrm{d} \chi_{0} / \mathrm{dT}\right)^{-1}$ (right) versus temperature. The lines are fits to the data as described in the text.

(c) Modified Arrott plots using $\beta=0.45$ and $\lambda=0.95$ as described in the text.

Applying Equation (3) to analysis of the critical isotherm at $\mathrm{T}_{\mathrm{C}}$ leads to the exponent $\delta=3.07$ (inset to Fig. 2(a)). According to statistical theory [10], these critical exponents fulfill the Widom scaling relation: $\delta=1+\gamma / \beta$. Using the exponents $\beta=0.45$ and $\gamma=0.95$ determined above, the value of $\delta$ for $\mathrm{Ho}_{2} \mathrm{Fe}_{16} \mathrm{Mn}$ is calculated to be $\delta=3.11$ which is close to the value of $\delta=3.07$ determined from the critical isotherm analysis at $\mathrm{T}_{\mathrm{C}}$. In a similar manner, the values of $\beta, \gamma, \delta$ for $\mathrm{Ho}_{2} \mathrm{Fe}_{17}\left(\right.$ of $\mathrm{T}_{\mathrm{C}}=336 \mathrm{~K}$ ) and $\mathrm{Ho}_{2} \mathrm{Fe}_{15} \mathrm{Mn}_{2}\left(\right.$ of $\mathrm{T}_{\mathrm{C}}=302 \mathrm{~K}$ ) have been determined as $\beta=0.53, \gamma=0.91, \delta=2.72$ and $\beta=0.42, \gamma=0.87$ and $\delta=3.07$, respectively. It is well established that the order parameter of a phase transition around the magnetic transition temperature fluctuates over all available length scales and that these fluctuations smear out the microscopic details of the interactions in a system exhibiting a continuous phase transition [10]. The mean field interaction model for long range ordering has theoretical critical exponents of $\beta=0.5, \gamma=1.0$ and $\delta$ $=3.0$, while theoretical values based on the three dimensional Heisenberg model corresponding to short range interactions are $\beta=0.365, \gamma=1.386$ and $\delta=4.80$. The $\beta, \gamma$ and $\delta$ values that we have derived experimentally are generally similar to the mean-field model values, indicating that the ferromagnetic coupling for $\mathrm{Ho}_{2} \mathrm{Fe}_{17-\mathrm{x}} \mathrm{Mn}_{\mathrm{x}}$ compounds is a long-range interaction.

As a further test and cross-check of our critical exponent analyses, Fig. 2(c) shows the modified Arrot-plots, $\mathrm{M}^{1 / \beta}$ as a function of $(\mathrm{H} / \mathrm{M})^{1 / \gamma}$ for $\mathrm{Ho}_{2} \mathrm{Fe}_{16} \mathrm{Mn}$ using the values of $\gamma$ and $\beta$ obtained above. Fig. 2(c) demonstrates clearly that for higher values of the DC fields $\left(\mu_{0} \mathrm{H}>2 \mathrm{~T}\right)$ these modified Arrot-plots exhibit isothermal curves which are parallel to a high degree (parallel dashed lines are shown as a guide to the eye in Fig. 2(c)) indicating the self consistency of these exponents in describing the critical behaviour of $\mathrm{Ho}_{2} \mathrm{Fe}_{16} \mathrm{Mn}$. 
3.3 Magnetocaloric Effect: The isothermal entropy change $-\Delta S_{M}$ corresponding to a magnetic field change $\Delta B$ from $\mathrm{B}=0$ to value $\mathrm{B}$, has been derived from the magnetization data using the Maxwell relation [e.g. 7]. The changes in magnetic entropy $-\Delta S_{M}$ for $\mathrm{Ho}_{2} \mathrm{Fe}_{16} \mathrm{Mn}$ as functions of temperature and external field are shown in Fig. 3(a). The curves of $-\Delta S_{M}$ exhibit a broad peak around $\mathrm{T}_{\mathrm{C}}$ (typical
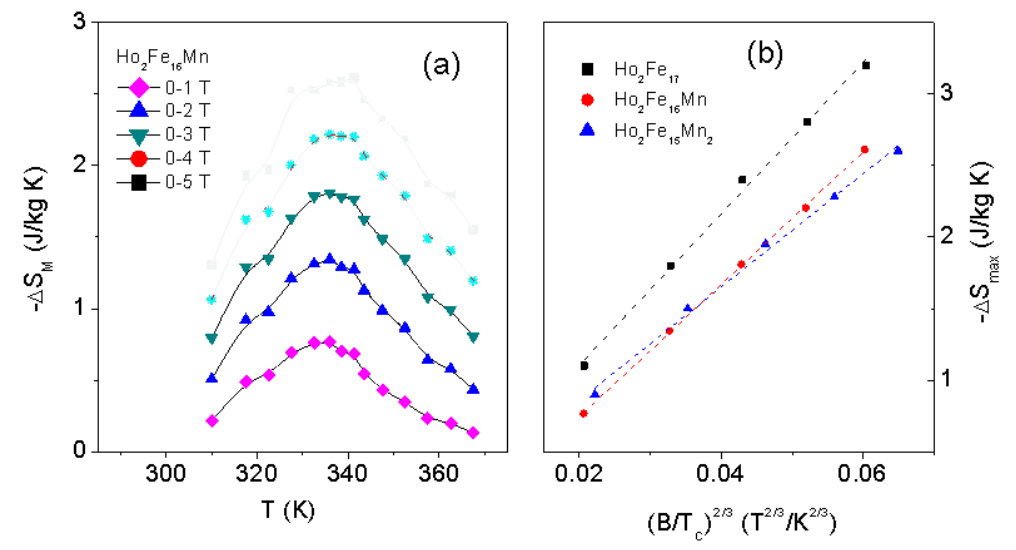

Fig. 3 (a) Temperature dependence of the isothermal magnetic entropy change $-\Delta S_{M}(T, B)$ as measured in magnetic fields up to $5 \mathrm{~T}$ for $\mathrm{Ho}_{2} \mathrm{Fe}_{16} \mathrm{Mn}$.

(b) Dependence of the entropy change $-\Delta S_{M}{ }^{\max }$ on the parameter $\left(\mathrm{B} / \mathrm{T}_{\mathrm{C}}\right)^{2 / 3}$ for $\mathrm{Ho}_{2} \mathrm{Fe}_{17-\mathrm{x}} \mathrm{Mn}_{\mathrm{x}}$ with $\mathrm{x}=0,1$ and 2 . The dashed lines represent linear fits to the data.

behaviour of a second order phase transition) with maximum values of $-\Delta S_{M} \sim 1.3$ $\mathrm{J} / \mathrm{kg} \mathrm{K}$ and $-\Delta S_{M} \sim 2.6 \mathrm{~J} / \mathrm{kg} \mathrm{K}$ for magnetic field changes of $\Delta \mathrm{B}=2 \mathrm{~T}$ and $\Delta \mathrm{B}=5$ $\mathrm{T}$ respectively. Mean field theory [12] predicts that $-\Delta S_{M}{ }^{\max }$ is proportional to $\left(\mathrm{B} / \mathrm{T}_{\mathrm{C}}\right)^{2 / 3}$ at second order phase transitions. Figure 3(b) shows a graph of maximum entropy change $-\Delta S_{M}{ }^{\max }$ plotted as a function of $\left(\mathrm{B} / \mathrm{T}_{\mathrm{C}}\right)^{2 / 3}$ for $\mathrm{Ho}_{2} \mathrm{Fe}_{17}$ ${ }_{x} \mathrm{Mn}_{\mathrm{x}}$ with $\mathrm{x}=0,1$ and 2. The linear fits to the data in Fig. 3(b) (fitted curves shown as dashed lines) demonstrate that the relationship $-\Delta S_{M}{ }^{\max } \propto\left(\mathrm{B} / \mathrm{T}_{\mathrm{C}}\right)^{2 / 3}$ is valid for the $\mathrm{Ho}_{2} \mathrm{Fe}_{17-\mathrm{x}} \mathrm{Mn}_{\mathrm{x}}$ system.

\section{Conclusions}

The critical behaviour of $\mathrm{Ho}_{2} \mathrm{Fe}_{17-\mathrm{x}} \mathrm{Mn}_{\mathrm{x}}$ compounds $(\mathrm{x}=0-2)$ has been investigated by combining a Mössbauer spectroscopy study and a detailed analysis of DC magnetization data around their ferromagnetic ordering temperatures of $\mathrm{T}_{\mathrm{C}} \sim 340$ $\mathrm{K}$. The four isomer shifts for the four inequivalent sites of their $\mathrm{Th}_{2} \mathrm{Ni}_{17}$-type or 
$\mathrm{Th}_{2} \mathrm{Zn}_{17}$ structures [5] are found to correlate well with the Wigner-Seitz cell volumes as observed previously [6]. The critical exponents determined for $\mathrm{Ho}_{2} \mathrm{Fe}_{17-\mathrm{x}} \mathrm{Mn}_{\mathrm{x}}$ are consistent with the theoretical predictions of the mean-field model, indicating that long range interactions dominate the critical behavior around $\mathrm{T}_{\mathrm{C}}$. The $\mathrm{Ho}_{2} \mathrm{Fe}_{17-\mathrm{x}} \mathrm{Mn}_{\mathrm{x}}$ compounds exhibit reasonable magnetocaloric behaviour as indicated by their isothermal magnetic entropy changes around the Curie temperatures $\left(T_{C}=336 \mathrm{~K}, \mathrm{~T}_{\mathrm{C}}=344 \mathrm{~K}\right.$ and $\mathrm{T}_{\mathrm{C}}=338 \mathrm{~K}$ for $\mathrm{x}=0,0.5$ and 1.0 respectively), suggesting that these iron-rich alloys allow scope for use as magnetic refrigeration materials close to room temperature.

\section{Acknowledgements}

This work is supported by a joint agreement between the Australian Nuclear Science and Technology Organisation and the University of Wollongong, and by a grant from the Australian Research Council (DP110102386). 


\section{References}

[1] Ekkes Brück, J. Phys. D: Appl. Phys. 38, R381 (2005)

[2] K.A. Gschneidner Jr., V.K. Pecharsky, A.O. Tsokol, Rep. Prog. Phys. 68, $1479(2005)$

[3] K. Mandal, A. Yan, P. Kerschl, A. Handstein, O. Gutfleisch and K.H. Müller, J. Phys. D: Appl. Phys. 37, 2628 (2004)

[4] H.Y. Chen, Y. Zhang, J.Z. Han, H.L. Du, C.S. Wang, Y.C. Yang, J. Magn. Magn. Mater. 320, 1382 (2008)

[5] J.L. Wang, S.J. Campbell, O. Tegus, C. Marquina, and M. R. Ibarra, Phys. Rev. B 75, 174423 (2007) and reference therein.

[6] J.L. Wang, S.J. Campbell, A.J. Studer, S.J. Kennedy and R. Zeng, Journal of Physics: Conference Series 200, 082025 (2010)

[7] J. L. Wang, A. J. Studer, S. J. Kennedy, R. Zeng, S. X. Dou and S. J. Campbell, J. Appl. Phys. 111, 07A911 (2012)

[8] Gary J. Long, O. A. Pringle, F. Grandjean, and K. H. J. Buschow, J. Appl. Phys. 72, 4845 (1992).

[9] J. L. Wang, S. J. Campbell, S. J. Kennedy, R. Zeng, S. X. Dou and G. Wu, J. Phys.: Condens. Matter 23, 2160002 (2011)

[10] M. E. Fisher, Rep. Prog. Phys. 30, 615 (1967).

[11] R.S. Freitas, C. Haetinger, P. Pureur, J.A. Alonso and L. Ghivelder, arxiv.org/pdf/cond-mat/0010108.

[12] H. Oesterreicher and F. T. Parker, J. Appl. Phys. 55, 4334 (1984). 


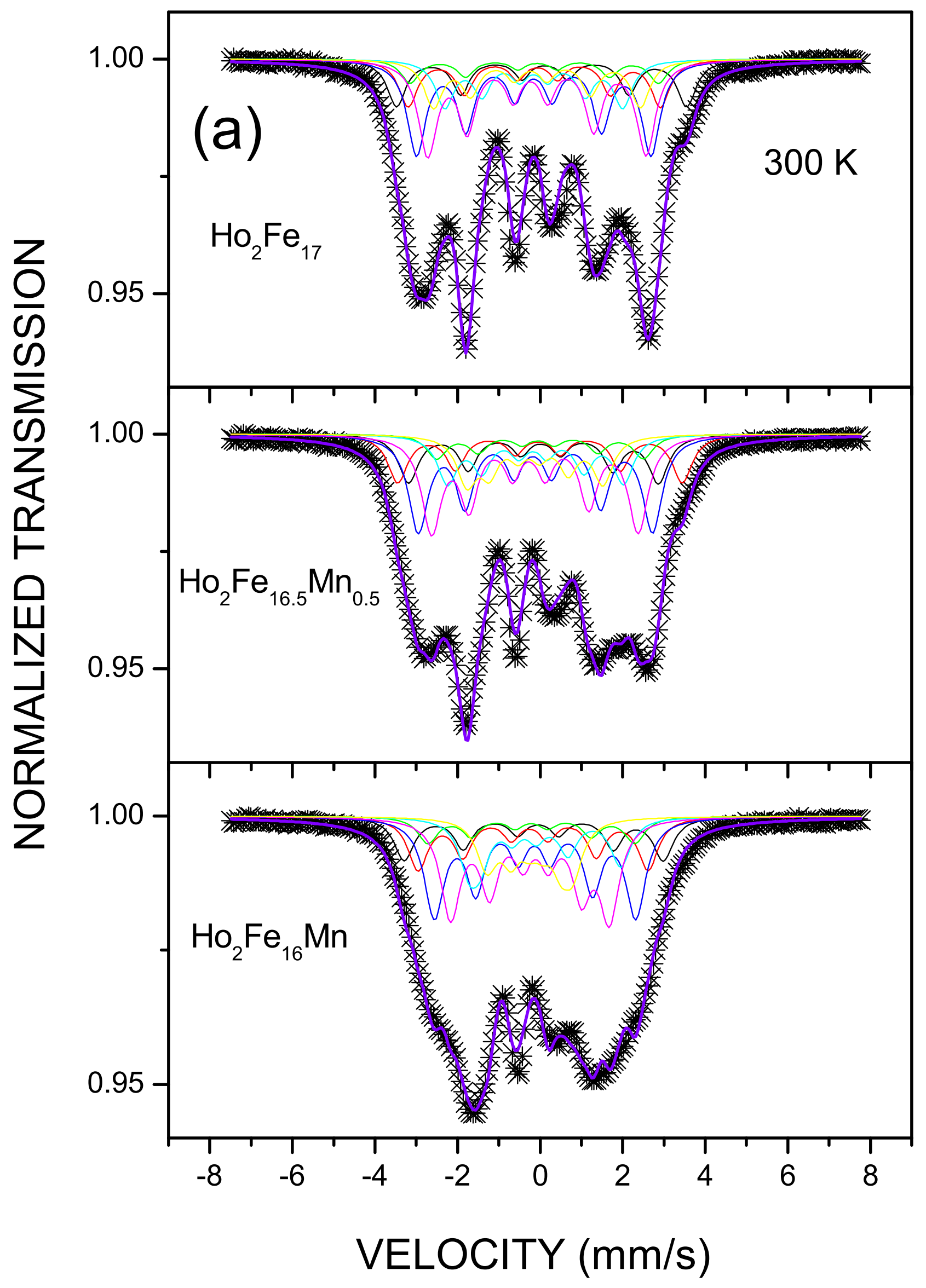




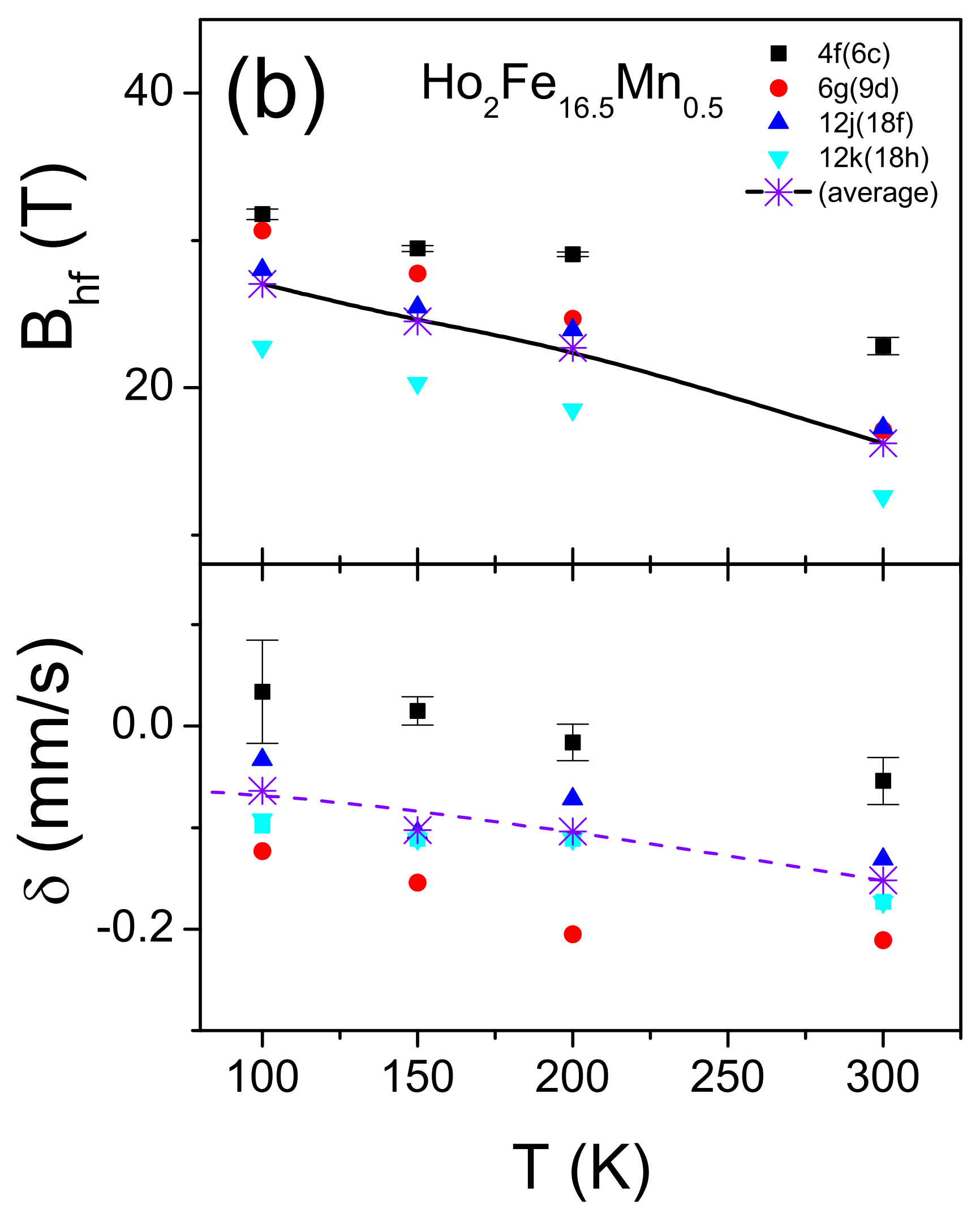



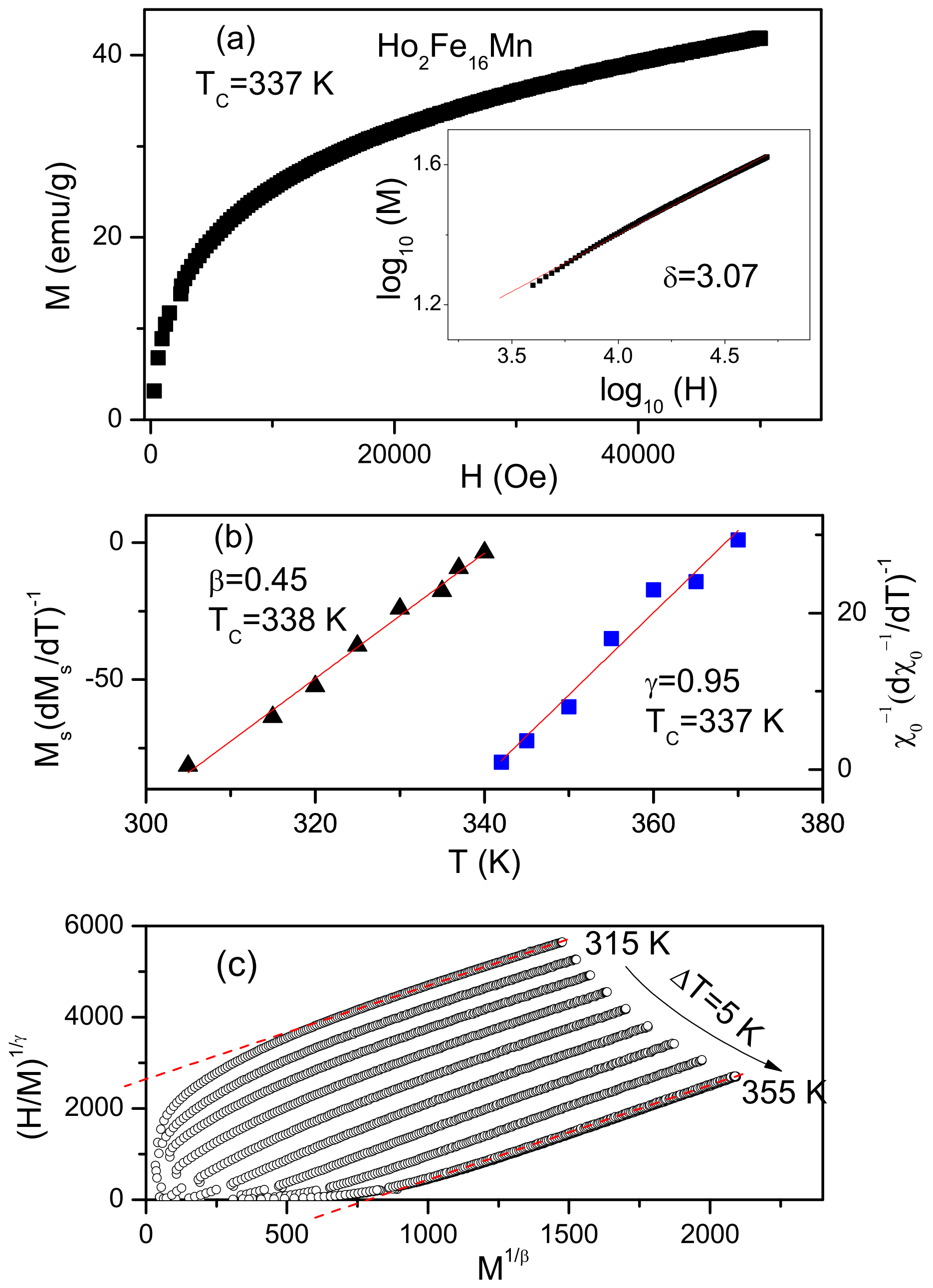

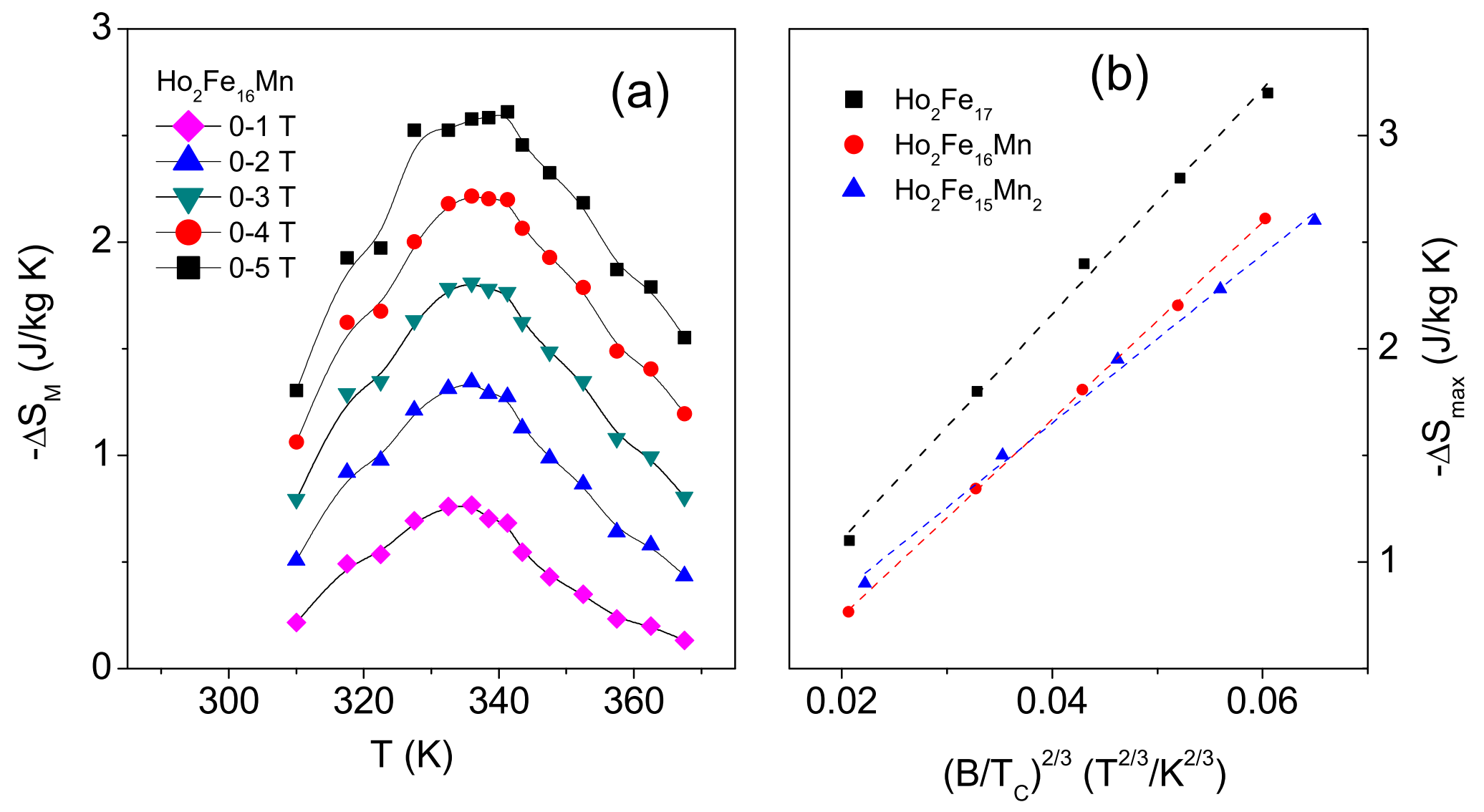